\begin{tabular}{cc|c|}
\hline \hline \hline & $\begin{array}{c}\text { International Journal of Current Research } \\
\text { and Academic Review }\end{array}$ \\
ISSN: 2347-3215 (Online) Volume 6 Number 7 (July-2018) \\
Journal homepage: http://www.ijcrar.com
\end{tabular}

doi: https://doi.org/10.20546/ijcrar.2018.607.001

\title{
Science as a Consecration to the Diabetics
}

\author{
Upasana Saha, Purva Sudesh Dharwadkar, Susmita Sur, V. Vishaharini and Madhu Malleshappa*
}

School of Sciences, Department of Life Sciences, Garden City University, Bengaluru, Karnataka, India

*Corresponding author

\begin{abstract}
Insulin, a hormone produced by the $\beta$ cells of Langerhans in the pancreas, regulates metabolism by allowing glucose uptake in our body from carbohydrates and hence helps in maintaining the blood glucose level. During diabetes treatment, insulin injections are provided to allow the body to process sugar and avoid complications from hyperglycemia. Growth of the global insulin market is propelled by several factors like increasing global prevalence of diabetes; rise in decrepit and obese populations and most importantly by propagation of diabetes management awareness and government impetus. According to 2017 census, Chengamanad, having a total population of 29,576 revealed, out of 14,475 males and 15,101 females, 25,132 are literates who are aware about Diabetes, its types and the necessity of insulin uptake for its treatment. The global insulin therapeutics market is expected to register a CAGR of $8.0 \%$ during forecast period, 2018 to 2023. North America dominates the market, due to its growing diabetic and obesity instances and even India is among the top five market leaders for insulin today. The increasing trend of awareness about diabetes and insulin is majorly due to the knowledge transfer about the disease through mass media such as television and newspapers that has whole heartedly contributed to public awareness. Family members and friends followed by doctors also play a very important role in distributing information about the disease especially to the people of the backward community. Although increasing literacy rate and distribution of knowledge is contributing to better public awareness; emphasis still needs to be given on periodic screening for diabetes and intake of insulin dosages correctly by patients if at all necessary. This report focusses on the contribution of knowledge transfer through different sources towards the increasing awareness of diabetes leading to the dynamic increase in Global insulin market.
\end{abstract}

\section{Article Info}

Accepted: 04 June 2018

Available Online: 10 July 2018

\section{Keywords}

Insulin; Diabetes; Knowledge

Transfer; Increase; Market

\section{Introduction}

Diabetes is a medical disorder that sparks off due to insufficient insulin production by the $\beta$ cells of Langerhans of the pancreas (Type I) or due to its defective response (Type II). Under normal conditions, level of blood glucose in the body is tightly controlled by insulin, a hormone produced by the pancreas. When the blood glucose hauls up, the hormone insulin is released from the $\beta$ cells of pancreas to standardize the glucose level. In diabetic patients, the absence or insufficient production or faulty response of insulin causes hyperglycemia.

Patients diagnosed predominantly by Type II Diabetes are advised lifestyle and diet changes which include routine exercises and nutritional balanced diet. But lifestyle changes and oral drugs for Type 2 diabetes are 
dubious to be a perpetual resolution. Over time, the pancreas tends to produce further less insulin until eventually it cannot meet the body's entail. Ultimately insulin, either in injected or infused dosage, is the most efficacious treatment for Type 2 diabetes. Diabetes mellitus (Type 1 and Type 2) is one of the most frequently encountered afflictions by the skilled medical experts. Globally, it is approximated its ubiquity among adults was 4\% in 1995 and this is anticipated to elevate to $5.4 \%$ by 2025 . Compared to other parts of the world, India has a higher prevalence of the disorder; North America being the leader.

Scientific education is one of the paramount constituent in ensuring better investigation and control of diabetes. There is also evidence to show that increasing awareness regarding diabetes and its hurdles has significant benefits including increase in consent to treatment, thereby decreasing the complications associated with diabetes. Although there have been small regional studies on the subject of diabetes awareness in India, there is no data at a national level or indeed even in a whole state of India on the awareness about diabetes.

\section{Results and Discussion}

The increasing worldwide statistics of diabetes is a concern

Diabetes is one of the most endemic diseases across the world and India being termed as the "Diabetic capital of the world" with as many as 50 million people suffering from type-2 diabetes; indeed has a challenge to face in the forthcoming years. A common illusion states that diabetes is non-fatal; but WHO reckons deaths of $80 \%$ diabetics in low and middle-income countries and projects that such deaths will double between 2019 and 2030.

Not only in India, it is surmised that approximately 415 million people are diabetic worldwide which implies 1 out of 11 in the world's adult population suffer from this malady out of which $46 \%$ cases are undiagnosed. This figure is expected to soar up to 642 million people worldwide by 2040 (Fig. 1-4).

\section{The escalating insulin demand reflects in the} flourishing market

Currently, approximately 100 million people around the world need insulin, the unavailability of which may lead to premature death. Hence it is now essential to establish a market to meet the demands of this 100 million and more population of diabetics. Rising ubiquity of diabetes is one of the important factors that revitalize the growth of the CIS insulin market. With the increasing demand and the flourishing market, the government supports and rising $R \& D$ in insulin product is projected to unveil remunerative growth in this industry.

The CIS insulin market is predominated by North America followed by European regions. Regional segmentation includes the current and forecast demand of CIS insulin in Asia Pacific, Latin America, and Middle East \& Africa with its further bifurcation into major countries including U.S. Germany, France, UK, China, Japan, India and Brazil. Asia Pacific is expected to witness significant growth over the prognostication period.

Contribution of the scientific world towards the acceptance of insulin by majority

\section{Insulin pills for diabetes management: a stepping stone towards early cure}

Indian scientists have done what medical science has been trying to achieve since 1930 - an insulin pill for diabetics; one of the biggest achievement in the world of scientific research. Since the crucial discovery of artificial insulin, millions of diabetics have had to inject themselves with this life-saving drug. Recently Indian scientists have formulated a new long-sought insulin pill that is expected to be a savior of the pain of daily shots (Fig. 5-7).

National programs and awareness campaigns for prevention and control of diabetes

This agitating scenario of increasing Diabetes has led the Indian Government to start the National Diabetes Control Programme on an experimental basis during the seventh five year plan in 1987 in some districts of Tamil Nadu, J \& $\mathrm{K}$ and Karnataka, but due to scarcity of funds in subsequent years this programme could not be amplified further in remaining states. However, during 1995-96, a sum of 12 lakh rupees was assigned for the programme and subsequently in 1997-98 an allocation of one core was made (Fig. 8).

The objectives of the Programme are:

Prevention of diabetes through identification of high-risk subjects and early intervention in the form of health education. 
Fig.1 Risk factors involved due to Diabetes

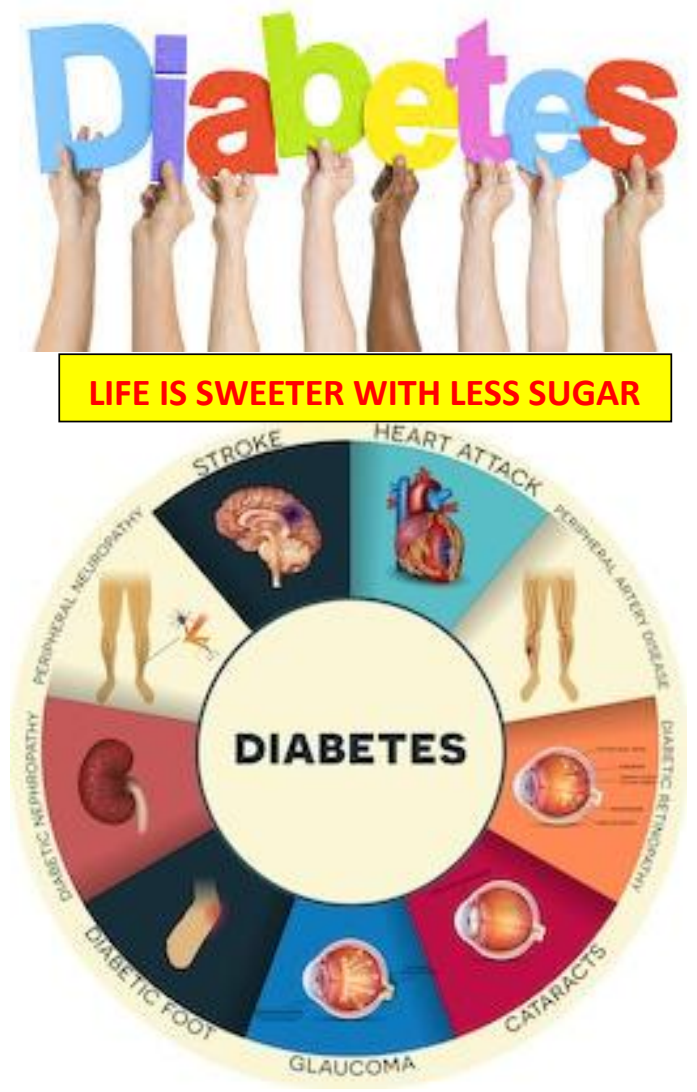

Fig.2 Revenue generation percentage from leading insulin markets

\section{Revenue in percentage}

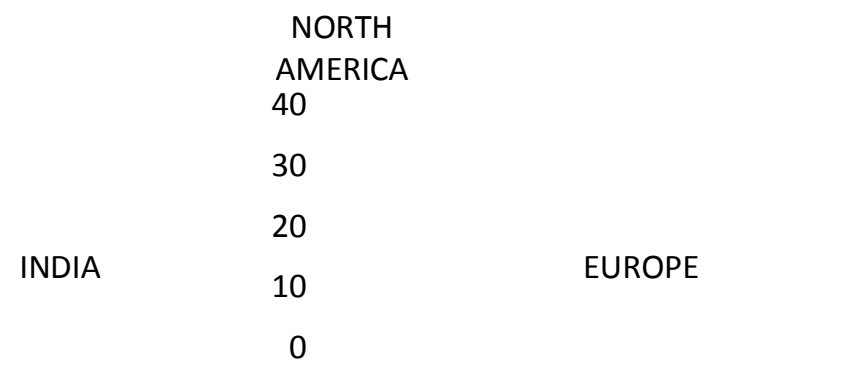

Revenue in percentage 
Fig.3 Percentage of diabetics in India in $2017(n=10442)$

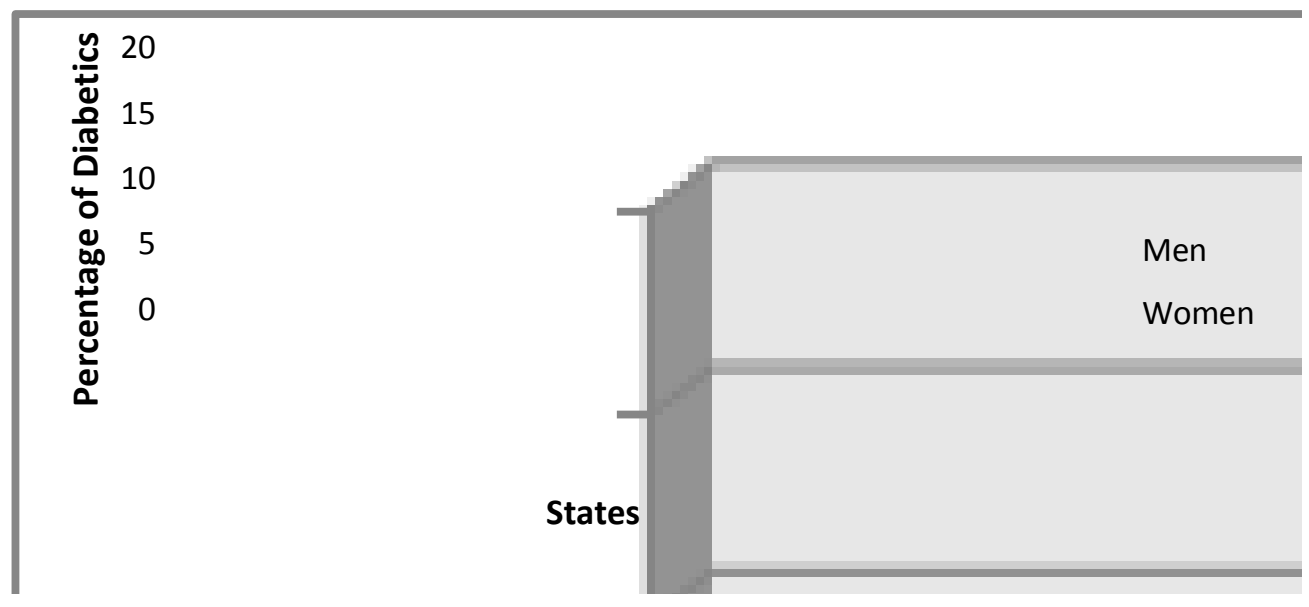

Fig.4 Current and projected prevalence rates for diabetes worldwide

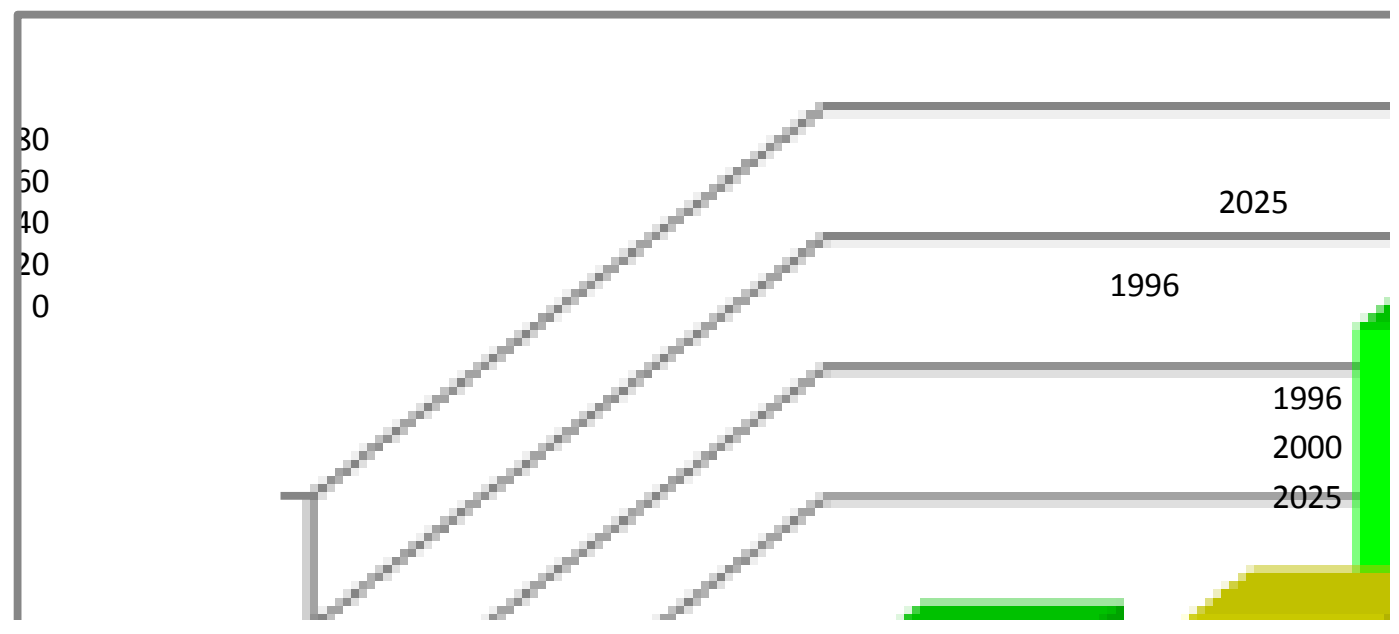

Fig.5 Rising market of insulin products with time in India

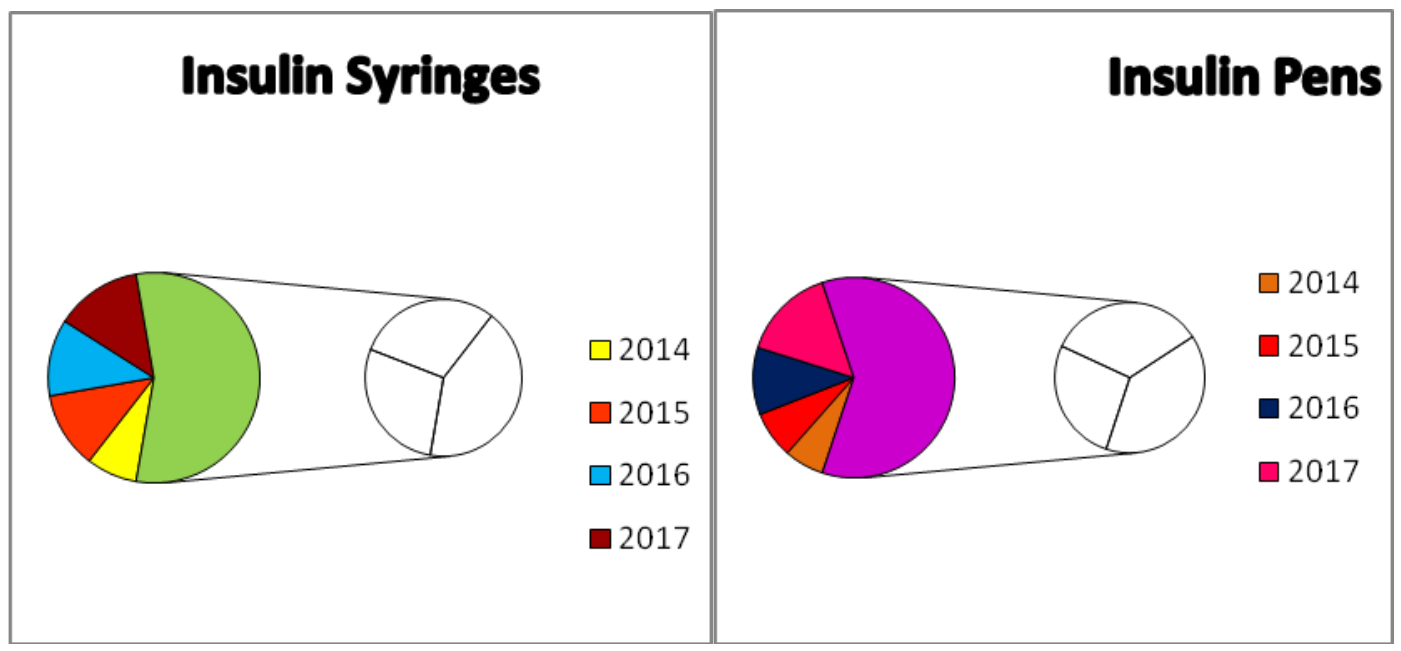




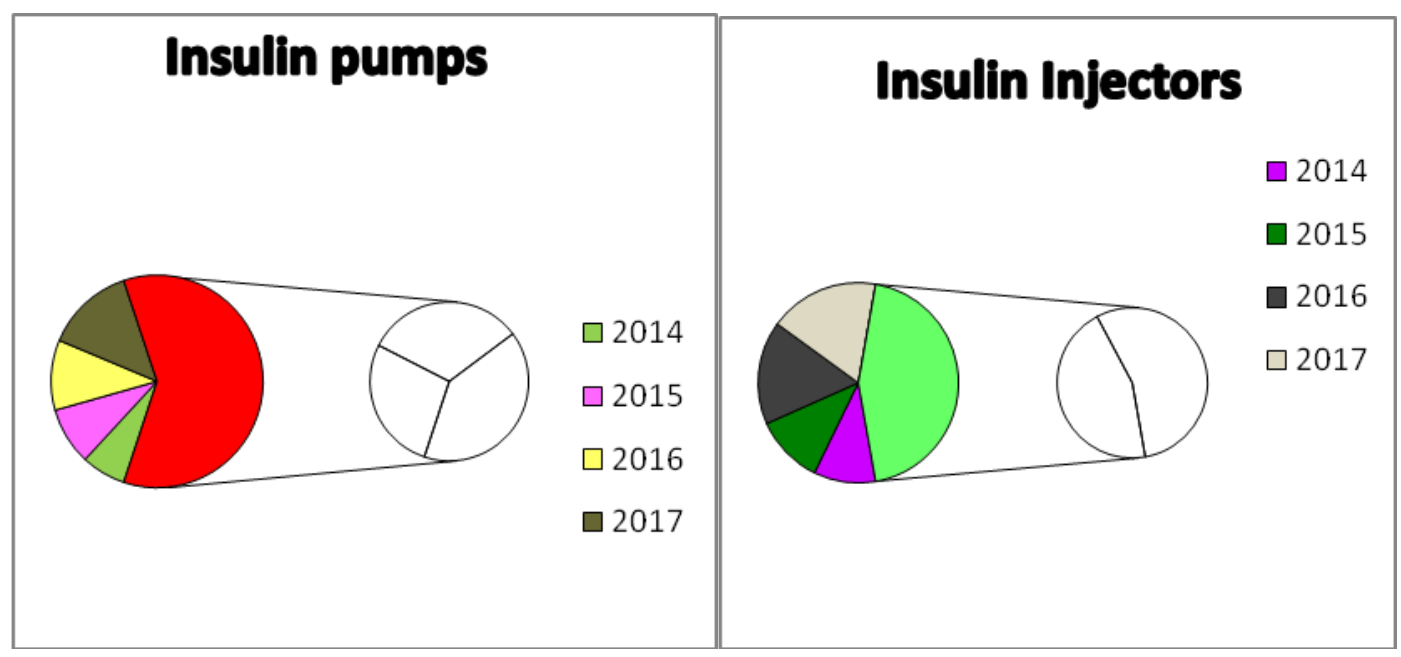

Fig.6 Global insulin market leaders

\section{INSULIN MARKET SHARE (\%) BY REGION (2016)}

NORTH AMERICA

LATIN AMERICA

EUROPE

ASIA PACIFIC

Fig.7 Insulin pills to cure diabetes without the injection pains

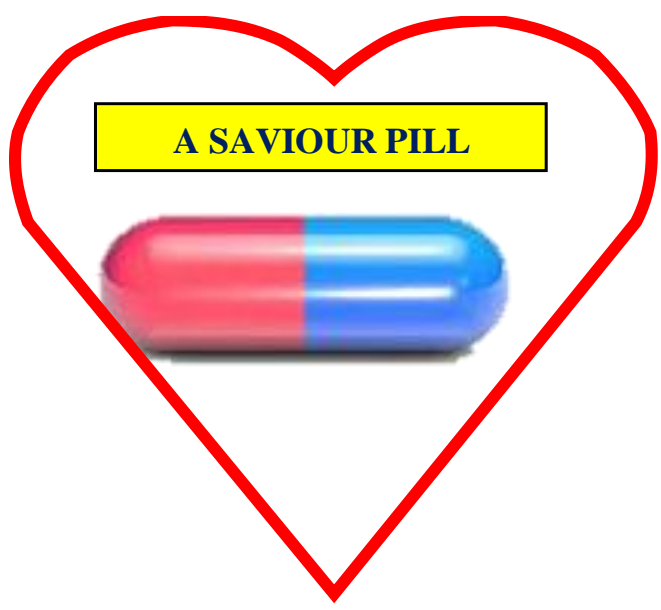


Fig.8 Go blue; support diabetes prevention

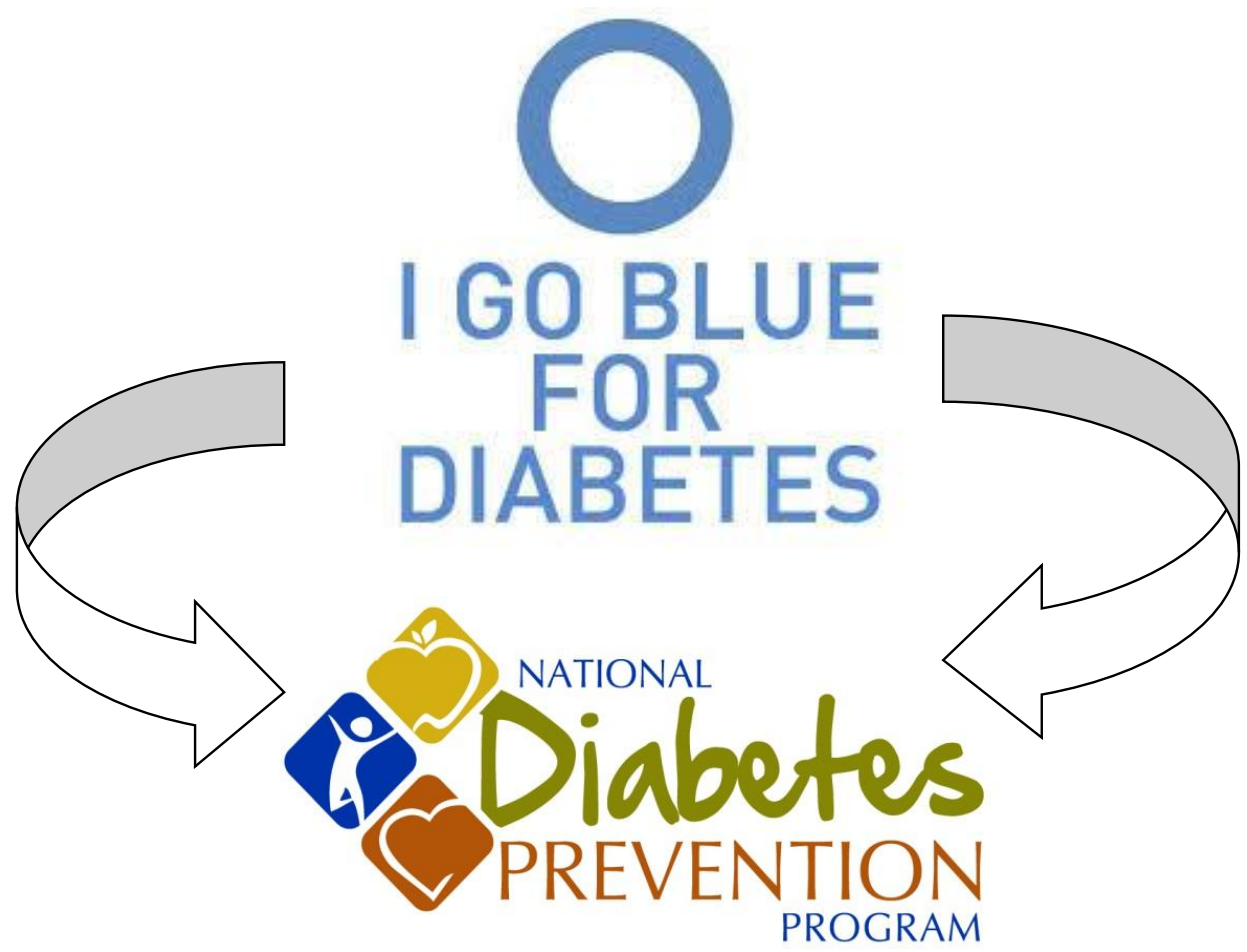

Fig.9 Herbal remedies for diabetics; a major footfall of scientific research

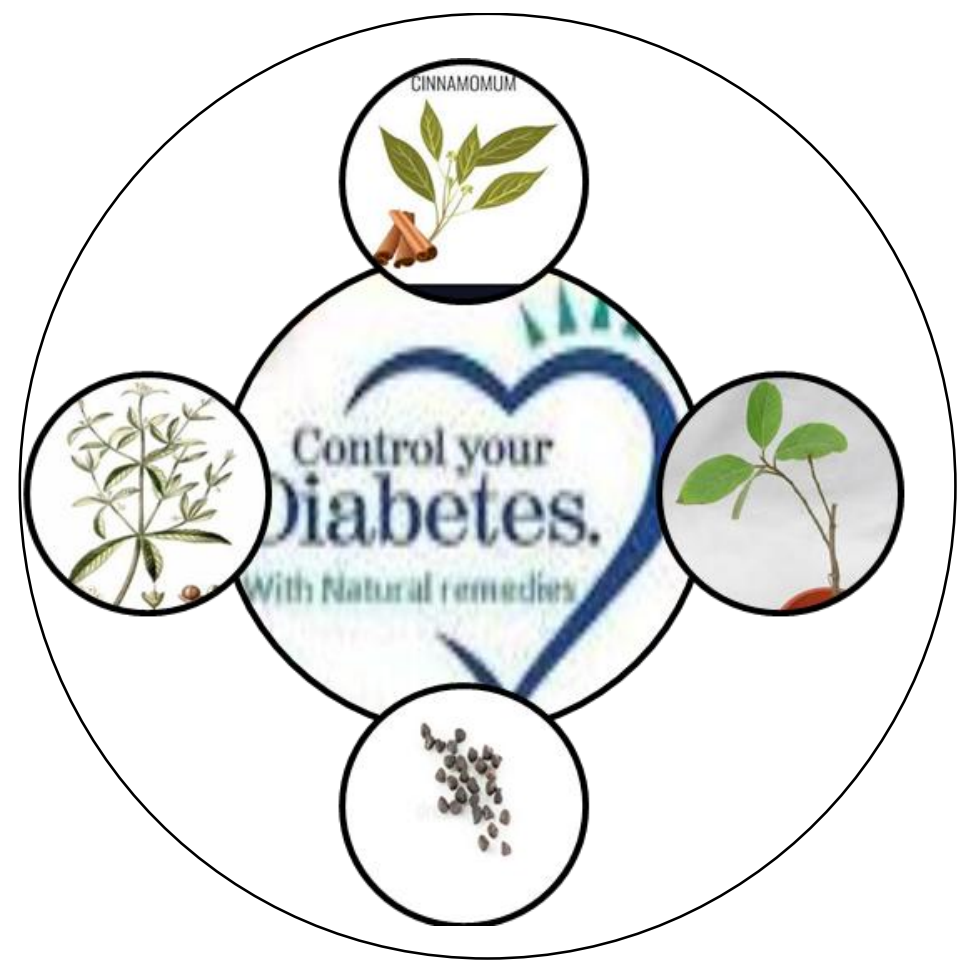


Early diagnosis of disease and appropriate treatment; reduction of morbidity and mortality with reference to the high-risk group;

Prevention of acute and chronic metabolic, cardiovascular, renal and ocular complications of the disease;

Provision of equal opportunities for physical attainment and scholastic achievement for the diabetic patients; and

Rehabilitation of those partially or totally handicapped diabetes people.

\section{Scientific herbal remedy}

Complementary treatments using herbal medicines draw the consciousness of many diabetics. Umpteen numbers of Ayurvedic herbs claim to reduce blood glucose level, therefore being less dependent on insulin injections by taking herbal medicines is indubitably alluring. However, the selection of herbs might depends on several factors, including the stage of advancement of diabetes, types of artifacts that the consumer are having, availability, reasonability as well as the safety profile of the herbs (Fig. 9).

Preclinical studies have crossed the doorstep of laboratories and reached to the bed-side of the patients. Several clinical studies in human patients have been conducted in recent years, reported that medicinal plants such as Scoparia dulcis, Cinnamomum cassia, Ficus racemosa bark and Portulaca oleracea L. seeds were shown to have antidiabetic potential. Subsequent research on laboratory on herbal products has reached to the diabetic patients by the brand name of Diabecon, Glyoherb and Diabeta Plus.

Thus, herbal supplements can be used as an adjuvant or as favorable alternative therapy for diabetic condition.

The International Diabetes Federation (IDF) has recently concluded its World Diabetes Day campaign. This yearlong awareness campaign, run by the IDF with the support of the World Health Organization (WHO), aims at informing the public of the causes, symptoms, complications and treatments associated with the condition. There are many such organizations that conduct such campaigns with the motive of transferring and spreading knowledge believing in "Prevention is better than cure". Scientific awareness and contribution of scientific research aims to make a Diabetes free India.

\section{References}

Dandona L, Dandona R, Naduvilath TJ, McCarty CA, Rao GN. Population based assessment of diabetic retinopathy in an urban population in Southern India. Br J Ophthalmol. 1999; 83: 937-40.

Dandona R, Dandona L, John RK, McCarty CA, Rao GN. Awareness of eye diseases in an urban population in Southern India. Bull World Health Organ. 2001; 79: 96-102.

Deepa M, Bhansali A, Anjana RM, Pradeepa R, Joshi SR, Joshi PP, et al., Knowledge and awareness of diabetes in urban and rural India: The Indian Council of Medical Research India Diabetes Study (Phase I): Indian Council of Medical Research India Diabetes 4. Indian J Endocrinol Metab. 2014; 18: 379-85. [PMC free article]

Jonas JB, Nangia V, Khare A, Matin A, Bhojwani K, Kulkarni M, et al., Prevalence and associated factors of diabetic retinopathy in rural central India. Diabetes Care. 2013; 36: e69.

Knowledge and awareness about diabetes mellitus and diabetic retinopathy in suburban population of a South Indian state and its practice among the patients with diabetes mellitus: A population-based study. Rameez Hussain, Bindu Rajesh, Anantharaman Giridhar, Mahesh Gopalakrishnan, Sanjai Sadasivan, Justin James, Pradeep Padickal Vijayan, and Nelson John. Indian J Ophthalmol. 2016 Apr; 64(4): 272-276.

Mohan D, Raj D, Shanthirani CS, Datta M, Unwin NC, Kapur A, et al., Awareness and knowledge of diabetes in Chennai - The Chennai Urban Rural Epidemiology Study [CURES-9] J Assoc Physicians India. 2005; 53: 283-7.

Murugesan N, Snehalatha C, Shobhana R, Roglic G, Ramachandran A. Awareness about diabetes and its complications in the general and diabetic population in a city in Southern India. Diabetes Res ClinPract. 2007; 77: 433-7.

Namperumalsamy P, Kim R, Kaliaperumal K, Sekar A, Karthika A, Nirmalan PK. A pilot study on awareness of diabetic retinopathy among nonmedical persons in South India. The challenge for eye care programmes in the region. Indian $\mathbf{J}$ Ophthalmol. 2004; 52: 247-51.

Namperumalsamy P, Kim R, Vignesh TP, Nithya N, Royes J, Gijo T, et al., Prevalence and risk factors for diabetic retinopathy: A population-based assessment from Theni district, South India. Br J Ophthalmol. 2009; 93: 429-34. [PubMed] 
Namperumalsamy $P$, Nirmalan PK, Ramasamy $K$. Developing a screening program to detect sight threatening diabetic retinopathy in South India. Diabetes Care. 2003; 26: 1831-5. [PubMed]

Padmaja KR, Rajiv R, Pradeep GP, Swati A, Kumaramanickavel G, Sharma T. Use of eye care services by people with diabetes - South India experience. Br J Ophthalmol (Online) May 2005.

Raman R, Paul PG, Padmajakumari R, Sharma T. Knowledge and attitude of general practitioners towards diabetic retinopathy practice in South India. Community Eye Health. 2006; 19: 13-4.

Raman R, Rani PK, Reddi Rachepalle S, Gnanamoorthy P, Uthra S, Kumaramanickavel G, et al., Prevalence of diabetic retinopathy in India: Sankara Nethralaya diabetic retinopathy epidemiology and molecular genetics study report 2. Ophthalmology. 2009; 116: 311-8.

Rema M, Deepa R, Mohan V. Prevalence of retinopathy at diagnosis among type 2 diabetic patients

\section{How to cite this article:}

Upasana Saha, Purva Sudesh Dharwadkar, Susmita Sur, V. Vishaharini and Madhu Malleshappa. 2018. Science as a Consecration to the Diabetics. Int.J.Curr.Res.Aca.Rev. 6(7), 1-8.

doi: https://doi.org/10.20546/ijcrar.2018.607.001 attending a diabetic centre in South India. $\mathrm{Br} \mathrm{J}$ Ophthalmol. 2000; 84: 1058-60.

Rema M, Premkumar S, Anitha B, Deepa R, Pradeepa R, Mohan V. Prevalence of diabetic retinopathy in urban India: The Chennai Urban Rural Epidemiology Study (CURES) eye study, I. Invest Ophthalmol Vis Sci. 2005; 46: 2328-33. [PubMed]

Saikumar S, Giridhar A, Mahesh G, Elias A, Bhat S. Awareness about eye diseases among diabetic patients: A survey in South India. Community Eye Health. 2007; 20: 16-7.

Somannavar S, Lanthorn H, Pradeepa R, Narayanan V, Rema M, Mohan V. Prevention awareness counseling and evaluation (PACE) diabetes project: A mega multi-pronged program for diabetes awareness and prevention in South India (PACE- 5) J Assoc Physicians India. 2008; 56: 429-35.

World Health Organization. Prevention of Blindness from Diabetes Mellitus. Geneva: WHO; 2006. 